\title{
AUTOEFICÁCIA E AUTOPERCEPÇÃO DE EMPREGABILIDADE: UMA INVESTIGAÇÃO ENTRE CONCLUINTES DO ENSINO SUPERIOR
}

\author{
SELF-EFFICACY AND SELF-PERCEPTION OF EMPLOYABILITY: \\ AN INVESTIGATION AMONG HIGHER EDUCATION GRADUATES
}

\author{
ANDRÉA VANESSA FERREIRA MENDONÇA \\ Universidade Federal do Pará \\ Administradora - Universidade Federal do Pará (UFPA) \\ Orcid: https://orcid.org/0000-0002-5359-6085. / E-mail: andreaferreira506@gmail.com \\ Rua Augusto Corrêa, 1 - Guamá - CEP 66.075-110. Belém - Pará - Brasil

\section{CARLOS ANDRÉ CORRÊA DE MATTOS} \\ Universidade Federal do Pará \\ Doutor em Ciências Agrárias - Universidade Federal Rural da Amazônia (UFRA) \\ Orcid: http://orcid.org/0000-0002-3027-7479 / E-mail: cacmattos@gmail.com \\ ÍCARO SARAIVA LAURINHO \\ Universidade Federal de Pernambuco \\ Mestrando do PPG em Ciências Contábeis (PPGCC) \\ Orcid: https://orcid.org/0000-0003-1648-8752 / E-mail: icarolaurinho@gmail.com

\section{BIANCA SUELEM DO NASCIMENTO FRANCO} \\ Universidade Federal do Pará \\ Mestranda do PPG em Gestão Pública para o Desenvolvimento (PPGGPD) \\ Orcid: https://orcid.org/0000-0003-2128-6477 / E-mail: nfrancobianca@gmail.com
}

\begin{abstract}
RESUMO
O objetivo do estudo é analisar a relação entre a crença da autoeficácia e a autopercepção de empregabilidade entre concluintes do ensino superior, e, identificar a presença de diferenças entre os concluintes de Administração e outros cursos superiores. A pesquisa ocorreu na Universidade Federal do Pará, caraterizada explicativa, de campo, com corte transversal e tratamento quantitativo de dados. Foram empregadas técnicas de estatística descritiva, inferencial (Teste t) e multivariada (RLM) em uma amostra de 205 formandos de seis cursos superiores. Os resultados confirmaram a relação de dependência entre a autoeficácia e a autopercepção de empregabilidade, convergindo com estudos internacionais. De modo geral, os estudantes se consideram autoeficazes e percebem de maneira positiva sua empregabilidade. Em relação às diferenças entre os formandos de administração e de outros cursos superiores, apesar de algumas variáveis com diferenças significativas, não foi possível afirmar que o comportamento seja diferente entre os entrevistados. As conclusões reforçam a contribuição das instituições de ensino não apenas na formação técnica, mas também no fortalecimento da confiança pessoal dos formandos.
\end{abstract}

Palavras-chave: Administração. Ensino Superior. Mercado de trabalho. Universidade. 


\begin{abstract}
This study aims to analyze the relationship between the belief in self-efficacy and the selfperception of employability among higher education graduates, and to identify the different beliefs among the graduates of Business Administration courses and of other higher education courses. This research was carried out at the Federal University of Pará, Pará State, Brazil, by explanatory study under field research with cross-section and quantitative treatment of data. Descriptive, inferential (t-test) and multivariate (RLM) statistical techniques were used in a sample of 205 trainees from six higher education courses. Results had corroborated the dependence relationship between self-efficacy and self-perception of employability, consistent with international studies. In general, students consider themselves self-effective, realizing their employability positively. Regarding the differences between the graduates of Business Administration courses and of other higher education courses, despite some variables with significant differences, it was not possible to state that the behavior has been different among the interviewees. The conclusions reinforce that the educational institutions contribute not only in technical training, but also in strengthening the trainees' personal confidence.
\end{abstract}

Keywords: Business Administration. Higher education. Labor market. University.

\title{
1 INTRODUÇÃO
}

A transição para o mercado de trabalho é um momento desafiador para o estudante, uma vez que ele deixa a universidade para disputar uma posição no mercado de trabalho como profissional. Assim, ele abandona a condição de aprendiz para transformar o conhecimento adquirido ao longo do curso superior em ações concretas, passando, portanto, a ser avaliado sob novas perspectivas, agora alinhadas aos interesses organizacionais. Movidos pelo forte desejo de atuar na profissão que escolheram (BARDAGI; BOFF, 2010; TEIXEIRA; GOMES, 2004), os recém-formados vivenciam um período de mudança e adaptação (LAMAS; AMBIEL; SILVA, 2014) que marca uma etapa de transição de carreira, exigindo, assim, competência para mobilizar diferentes recursos pessoais e, com isso, aumentar as possibilidades de superar as barreiras que surgirem com o maior sucesso possível.

A transição universidade-mercado assume um caráter eminentemente social, por ocorrer em diferentes intensidades com todos os profissionais recém-formados (GLASER; BARDARGI, 2011). Nessa fase, a resiliência, a flexibilidade e a capacidade de lidar com a incerteza são características diferenciadoras, capazes de facilitar o enfrentamento das adversidades, seja nas disputas por vagas de empregos, concursos públicos, ou mesmo, empresas concorrentes para aqueles que almejam ser donos do próprio negócio.

Magalhães e Teixeira (2013) destacam os esforços de pesquisadores internacionais para identificar os fatores de ordem comportamental capazes de influenciar a conduta dos estudantes e, com isso, contribuírem para o desenvolvimento de estratégias que, ao serem implementadas durante o curso universitário, facilitem o processo de adaptação dos estudantes ao mercado de trabalho. Pois, conforme Lamas, Ambiel e Silva (2014), as vivências ao longo da formação universitária podem promover múltiplas habilidades, não se limitando às de ordem técnica, específicas da formação profissional.

Desta forma, ao tratar da inserção no mercado de trabalho de profissionais recémformados e dos inúmeros fatores capazes de influenciá-los, destacam-se os estudos sobre 
autoestima, extroversão e realização pessoal (KANFER; WANBER; KANTROWITZ, 2001), controle situacional (KANFER et al., 2001), comprometimento (WANBERG; KANFER; ROTUNDO, 1999), experiência pessoal e percepção de empregabilidade (CHEN; LIM, 2012), autoeficácia (ZIKIC; SAKS, 2009), entre outros. Por outro lado, Bardagi e Boff (2010) complementam e colocam em evidência aspectos externos, essencialmente incontroláveis, que influenciam fortemente na transição dos recém-formados para o mercado de trabalho, como, por exemplo, oferta de vagas de emprego, tanto no mercado de trabalho em geral, quanto na profissão do estudante, taxa de crescimento da economia, salários e benefícios, entre outros.

Nesse contexto, a presente investigação concentrou esforços em reunir elementos para responder ao problema de pesquisa: quais características da autoeficácia são capazes de influenciar na autopercepção de empregabilidade de estudantes concluintes de cursos universitários? Complementarmente, a pesquisa levantou como questionamento se existe diferença na crença de autoeficácia e na percepção de empregabilidade entre concluintes do curso de bacharelado em Administração e outros cursos universitários. A escolha por Administração ocorreu pela projeção do curso, que, juntamente, com Direito e Pedagogia, forma os três cursos superiores com maior número de vagas no Brasil, conforme o Censo da Educação Superior de 2018 (INSTITUTO NACIONAL DE ESTUDOS E PESQUISAS EDUCACIONAIS ANÍSIO TEIXEIRA, 2019).

Assim, com o objetivo de analisar aspectos da autoeficácia e da autopercepção de empregabilidade, este estudo adotou a conceituação de Peixoto, Janissek e Aguiar (2015, p.177), que compreendem a autopercepção de empregabilidade como "um indicador da possibilidade de se adquirir um trabalho e se manter atrativo nos mercados interno e externo de trabalho". Isso posto, para esses autores, a manutenção da empregabilidade assume um caráter pessoal que se sustenta na autoavaliação pessoal quando considera as próprias competências em comparação com as demandas do mercado de trabalho.

Por outro lado, a autoeficácia, na perspectiva de Bandura (1989), consiste na conviç̧ão da capacidade de enfrentar e superar desafios, materializando, por consequência, o quanto o indivíduo se considera apto a alcançar conquistas nas atividades que desenvolve. Isto posto, quanto mais forte a crença da autoeficácia, maiores serão a confiança e a conviç̧ão pessoal para enfrentar situações e se recuperar rapidamente de eventuais insucessos, fracassos e frustrações.

O caráter inovador da presente investigação está em reunir os construtos autoeficácia e autopercepção de empregabilidade em condição de dependência e, com isso, testar a hipótese de que a percepção de empregabilidade depende de aspectos presentes na crença de autoeficácia. Com isso, busca-se observar se a relação de dependência se confirma em uma amostra de estudantes brasileiros, a exemplo de estudos internacionais como Luthans, Yousset e Avolio (2007) e Liu et al. (2014).

Para tanto, o estudo foi organizado em cinco seções, incluindo esta introdução. $\mathrm{Na}$ sequência, a Fundamentação Teórica, traz estudos sobre aspectos contemporâneos da empregabilidade, esclarece a relação entre autoeficácia e percepção de empregabilidade e trata da transição dos profissionais recém-formados para o mercado de trabalho. A terceira seção destaca os procedimentos metodológicos, mais especificamente, a classificação da pesquisa e as técnicas de amostragem, coleta e tratamento dos dados. A seção de Apresentação de Resultados, terceira seção, inicia com o perfil dos entrevistados e mostra os resultados da regressão linear múltipla (RLM), técnica selecionada para analisar a relação de dependência e, posteriormente, compara estudantes do curso de Administração com 
estudantes de outros cursos superiores. Na última seção, Considerações Finais, são mostradas as implicações teóricas e práticas do estudo, além das limitações e sugestões para pesquisas futuras.

\section{FUNDAMENTAÇÃO TEÓRICA}

A seção está organizada em três subseções que versam sobre as mudanças ocorridas no mercado de trabalho no século XXI, a relação entre autoeficácia e autopercepção de empregabilidade e os desafios enfrentados pelos universitários na transição para o mercado de trabalho.

\subsection{A EMPREGABILIDADE E O MERCADO DE TRABALHO CONTEMPORÂNEO}

O mercado de trabalho tem passado por grandes mudanças ao longo das últimas décadas. Peixoto, Janissek e Aguiar (2015) atribuem essas mudanças principalmente às alterações nos cenários político-econômicos, assim como ao intenso avanço tecnológico (ALMEIDA, 2007). Nesse contexto, um amplo conjunto de acontecimentos alterou tanto as estruturas organizacionais em si, quanto os meios de produção e, por conseguinte, refletiram-se nas relações de emprego. Assim, especialmente a partir da década de 1980, a reestruturação produtiva mostrou novas formas de relacionamentos organizacionais que desencadearam mudanças, tanto interna, quanto nas relações das organizações entre si e com seus mercados de atuação, esse processo acabou por exigir novas competências dos trabalhadores.

Práticas como a flexibilização do trabalho, terceirização, empowerment, contratos temporários, teletrabalho, entre outras, expandiram a diversidade de formas de empregos e propiciaram um cenário empregatício no qual a competividade se mostrou progressivamente mais acirrada e cada vez mais determinante para a conquista dos melhores postos de trabalho, tendo essa condição exigido dos trabalhadores maior capacidade de adaptação, além de uma constante busca por conhecimento e qualificação para se destacar dos demais trabalhadores (RUEDA; MARTINS; CAMPOS, 2004).

Assim, ao longo do tempo, as organizações deixaram de garantir estabilidade e manutenção do emprego, não exigindo mais fidelidade dos trabalhadores. Por consequência, na reorganização do mercado de trabalho moderno, os próprios trabalhadores passaram a assumir a responsabilidade pelo futuro de suas carreiras e pela manutenção da própria empregabilidade, tendo em vista que as organizações adotaram novas e flexíveis práticas de contratação e, com isso, acabaram por reduzir o número de postos de trabalho. Por outro lado, os trabalhadores ganharam liberdade para conciliar diferentes tipos de empregos em diversas organizações (MALSCHITZKY, 2004).

Conforme Malschitzky (2004), as transformações que ocorreram no mercado de trabalho fizeram com que os requisitos exigidos pelas empresas se voltassem para uma melhor qualificação profissional e desenvolvimento de habilidades para trabalhar de forma organizada e colaborativa, assumindo responsabilidades pela própria atividade. Com isso, as organizações passaram a valorizar conhecimentos como planejamento pessoal, capacidade de autocontrole e habilidade para solucionar problemas, não somente para realizar tarefas e cumprir ordens. Dessa forma, um perfil diferente de trabalhador foi traçado, destacando-se a preocupação em buscar continuamente conhecimentos atualizados e desenvolver constantemente novas competências para se manter ativo no mercado de trabalho (FERREIRA FILHO; ANDRADE; SOUZA, 2013). Nesse contexto, a empregabilidade passou a ser 
conceituada em diversos estudos (RUEDA; MARTINS; CAMPOS, 2004; MALSCHITZKY, 2004; PEIXOTO; JANISSEK; AGUIAR, 2015) como o conjunto de práticas com as quais os indivíduos desenvolvem habilidades pessoais e acumulam conhecimentos para sua inserção ou permanência no mercado de trabalho, seja ele formal ou não.

Contudo, na perspectiva individual, a empregabilidade é um construto de caráter psicossocial, que se materializa na relação dos trabalhadores com as organizações. Por óbvio, envolve um conjunto de convicções pessoais, quanto à própria capacidade em conquistar, manter ou substituir um emprego. Esse construto, denominado de autopercepção de empregabilidade, sustenta-se na avaliação pessoal sobre a própria empregabilidade e, com isso, reunir aptidões e requisitos valorizados pelo mercado de trabalho (PEIXOTO, JANISSEK, AGUIAR, 2015). Entretanto, apenas ter as competências não garante inserção ou permanência no emprego, sobretudo nas fases iniciais de construção de carreira, quando o indivíduo tem que acreditar na capacidade pessoal em articular conhecimento e persistência para ter sucesso na busca pelo emprego. Assim, além da autopercepção de empregabilidade, é necessária a convicção pessoal quanto a própria capacidade de enfrentar e superar desafios que se sustenta no que Bandura (1989) denominou de autoeficácia.

\subsection{A AUTOEFICÁCIA E A EMPREGABILIDADE: CONCEITUAÇÃO E RELAÇÃO}

Bandura (1994) conceitua autoeficácia como a confiança do indivíduo em suas habilidades pessoais para preparar e executar fluxos de ações necessárias para realizar uma tarefa com sucesso. O conceito de autoeficácia tem origem na Teoria Social Cognitiva (TSC), disseminada pelo próprio Bandura, o qual defende que existe uma relação triádica entre fatores ambientais, pessoais e comportamentais, que, ao interagirem, são determinantes para a construção dos pensamentos e das ações do indivíduo e, com isso, constituem uma relação mútua de influência entre o indivíduo e o meio, no qual o indivíduo tanto pode influenciar, quanto ser influenciado pelo ambiente, visto ser ele capaz de construir e destruir seu entorno, assumindo posição tanto de produtor, quanto de produto do ambiente, constituindo um processo essencialmente circular (GOMES, 2014; BANDURA, 1989; MARTÍNEZ; SALANOVA, 2006).

Ferreira (2010) destaca que a TSC vai de encontro às teorias behavioristas, que defendem que o ambiente é responsável por controlar e moldar as ações humanas, sendo o homem um ser passível no processo de mudança, incapaz de exercer influência sobre o meio. A autoeficácia, por sua vez, está relacionada à confiança gerada pela autoavaliação das capacidades pessoais para cumprir determinada atividade. Assim, a autoeficácia não se relaciona com as habilidades em si, mas, sim, com o julgamento das próprias capacidades, envolvendo, portanto, a compreensão de se sentir apto ou não para realizar determinada tarefa com êxito (FERNANDES, 2011; GOMES, 2014). A TSC acredita que o comportamento humano é afetado fortemente pelas crenças de autoeficácia, portanto relacionando-se ao self, ou, dito de outra forma, relaciona-se com as expectativas acerca de si mesmo, que têm papel fundamental nas escolhas e ações projetadas pelos indivíduos ao propiciarem a confiança para realizar as tarefas com sucesso (RAMOS; PAIXÃO; SILVA, 2007).

Diversos estudos (BANDURA, 1994; POLYDORO; GUERREIRO, 2010; CORREIA, 2011; FERNANDES, 2011; SANTOS; MOGNON; JOLY, 2011; GOMES, 2014) afirmam que as crenças de autoeficácia são influenciadas por quatro fontes de informação ou experiências de aprendizagem, sendo elas: (1) experiência direta, (2) experiência vicária, (3) persuasão social e (4) estados físicos e emocionais. 
A experiência direta decorre da autoavaliação perante determinadas atividades. Portanto, quando as atividades são realizadas com sucesso, as crenças de autoeficácia se fortalecem, enquanto diante dos fracassos, elas diminuem (CORREIA, 2011). A experiência vicária, por sua vez, está relacionada com a observação de terceiros, tidos como modelos pelo indivíduo. Assim, o observador absorve as experiências de sucesso do modelo e, com isso, fortalece as próprias crenças de autoeficácia, posto que o exemplo do modelo mostra ao observador que, assim como o modelo conseguiu, ele também pode conseguir alcançar conquistas pessoais semelhantes, ou mesmo outras, que são almejadas por ele (GOMES, 2014).

A persuasão social, outra fonte de autoeficácia, resulta de informações obtidas de um amplo conjunto de agentes sociais. Assim, a expressão verbal de avaliações e os julgamentos de terceiros, especialmente, quando emanam de fontes valorizadas pelos indivíduos, são capazes de reforçar positivamente as conviç̧ões, capacidades e desempenho pessoal em determinadas atividades (FERREIRA, 2010), fortalecendo ou enfraquecendo as crenças de autoeficácia. Já quanto aos estados físicos e emocionais, eles se mostram como respostas do organismo na condição de cansaço, tensão, alegria, ansiedade, medo etc., capazes de influenciar na avaliação pessoal sobre seu próprio desempenho (PELISSONI, 2007).

Assim, indivíduos com crenças de autoeficácia fortalecidas, quando são colocados diante de situações que exigem maior esforço e necessitam mais de suas capacidades, serão mais resistentes ao estresse de enfrentá-las (BARDAGI; BOFF, 2010). Segundo Correia (2011), as crenças de autoeficácia exercem influência, tanto nos sentimentos, quanto nos pensamentos, comportamentos e na motivação pessoal dos indivíduos, e isso ocorre por meio de quatro processos: (1) cognitivos, (2) motivacionais, (3) afetivos e (4) seletivos.

Os processos cognitivos relacionam-se à avaliação antecipada das possíveis consequências de uma ação, nela os indivíduos estabelecem objetivos e avaliam possíveis resultados, sendo esses objetivos influenciados pela autoavaliação, que considera as próprias capacidades pessoais. Os processos motivacionais estão relacionados ao tempo e ao esforço disponibilizados para a realização de uma tarefa e à capacidade de perseverar e resistir diante de falhas e diversidades (BANDURA, 1994). Os processos afetivos pautam-se nas reações emocionais assim como nas estratégias para enfrentar o estresse ou na consternação diante de uma situação de adversidade (CORREIA, 2011). Os processos seletivos, por sua vez, relacionam-se à escolha de ambientes e de atividades favoráveis ao indivíduo, em que ele se sinta capaz de realizar algo com sucesso, evitando ocasiões que possam extrapolar suas habilidades ou colocá-las em risco (BANDURA, 1994; GOMES, 2014).

A autoeficácia não é uma atitude geral perante a vida, ao contrário, ela é direcionada a atividades específicas, podendo, por consequência, ser afetada pelo reconhecimento por parte do indivíduo a respeito das próprias habilidades e da aprendizagem de novos conhecimentos. Indivíduos que mostram elevada percepção de autoeficácia, normalmente são mais capazes para lidar com os insucessos, compreendendo-os como parte do processo de aprendizagem e avaliando seu desempenho de acordo com seu nível de instrução, aceitando com maior facilidade atividades mais complexas e desafiadoras. Entretanto, aqueles com baixos níveis de autoeficácia geralmente acreditam que as habilidades são herdadas e fixas, o que instiga a adoção de tarefas mais simples nas quais haja uma possibilidade menor de ocorrerem erros, pois para estas pessoas os erros são ameaças ao seu desempenho (FERNANDES, 2011).

No âmbito vocacional, a autoeficácia tem sido objeto de estudo de várias pesquisas (TEIXEIRA; GOMES, 2004; PELISSONI, 2007; GLASER; BARDAGI, 2011; CORREIA, 2011; SILVA; 
FERRAZ; OSWALDO, 2012) relacionadas, entre outros aspectos, à etapa de inserção do jovem no mercado de trabalho e às mudanças nessa fase da vida. Nesse sentido, entende-se que a presença de autoeficácia na transição para o mercado de trabalho pode contribuir para conseguir um emprego e se adaptar a ele, uma vez que indivíduos com maior autoeficácia são mais resistentes às frustrações e mais persistentes para buscar oportunidades de empego (CORREIA, 2011).

\subsection{A TRANSIÇÃO PARA O MERCADO DE TRABALHO DO RECÉM-FORMADO}

A preocupação do jovem com a carreira profissional ao término da faculdade sempre foi evidente, mas as mudanças no mercado de trabalho, principalmente em consequência de cenários econômicos, sociais e tecnológicos (ALMEIDA, 2007; PEIXOTO, JANISSEK; AGUIAR, 2015), têm impactado na percepção das competências pessoais para a conquista de uma vaga de emprego e influenciado na capacidade dos novos profissionais para enfrentar os desafios da transição da universidade para o mercado de trabalho (SILVA; FERRAZ; OSWALDO, 2012).

Nesse contexto, o diploma de graduação por si só não garante mais nem o emprego, muito menos o sucesso profissional, como ocorria no passado (TEIXEIRA; GOMES, 2004). O mercado de trabalho moderno exige mais dos profissionais do que certificados e cartas de recomendação, tendo em vista que as organizações estão voltadas para identificar capacidades e habilidades pessoais do candidato, portanto, as competências que os estudantes desenvolveram ao longo do curso que eles podem aplicar na prática (SANTOS; MOGNON; JOLY, 2011). Nesse contexto, há necessidade de profissionais hábeis o suficiente para formar uma boa rede de network, que sejam flexíveis e consigam se adaptar às diferentes exigências laborais (TEIXEIRA; GOMES, 2004).

A transição da universidade para o mercado de trabalho marca transformações pessoais e profissionais para os estudantes e sinaliza o início do desenvolvimento de uma carreira (CAIRES; ALMEIDA, 1998 apud CORREIA, 2011). É um momento que exige capacidade de mobilizar recursos pessoais e de enfrentar situações novas e, até certo ponto, inusitadas (MAGALHÃES; TEIXEIRA, 2013), caracterizando um grande desafio para muitos recém-formados.

Durante a vida acadêmica, um amplo conjunto de aspectos pode provocar desapontamentos e frustrações no universitário, como a elevada carga de atividades, baixos rendimentos, evasão de colegas, restrições no poder aquisitivo, falta de oportunidades de estágio, entre outros. Esses aspectos, em certa medida, influenciam na identificação e no comprometimento do estudante com a profissão escolhida e podem alterar a capacidade de lidar com situações conflituosas e de difícil solução como a competição no mercado de trabalho (SILVA; FERRAZ; OSWALDO, 2012). Além disso, outros aspectos como o elevado número de recém-graduados, o desemprego ou o subemprego após o término do curso universitário podem influenciar na insegurança e no desconforto do estudante na sua inserção no mercado de trabalho (SANTOS; MOGNON; JOLY, 2011).

Sendo assim, fortalecer a crença da autoeficácia auxilia os jovens no final da graduação, momento em que são estabelecidos os planos para a vida pessoal e profissional (SANTOS; MOGNON; JOLY, 2011). As crenças de autoeficácia nesse momento são determinantes para o esforço e a resiliência diante de dificuldades e acabam por influenciar diretamente no posicionamento do estudante em relação aos requisitos profissionais exigidos pelo ambiente de trabalho, representando um fator psicológico necessário ao processo de empregabilidade (GOMES, 2014). 
Por conseguinte, cabe à instituição de ensino promover mecanismos que favoreçam, durante o período da academia, o desenvolvimento de crenças de autoeficácia para que, ao final do curso, o estudante seja mais confiante em suas próprias capacidades para lidar com essa transição, pois indivíduos que têm baixas crenças de autoeficácia desenvolvem sentimentos pessimistas e são mais ansiosos, mostrando maior dificuldade para conseguir alcançar suas metas profissionais (CORREIA, 2011).

\section{METODOLOGIA}

Os procedimentos utilizados na pesquisa, segundo Gil (2014), caracterizam um estudo explicativo, feito na forma de pesquisa de campo, com corte transversal e tratamento quantitativo de dados. Os estudos explicativos "têm como preocupação central identificar os fatores que determinam ou que contribuem para a ocorrência dos fenômenos" (GIL, 2014, p. 28). Esse tipo de pesquisa se fundamenta, essencialmente, em hipóteses causais e representa o maior aprofundamento metodológico possível em pesquisas sociais (GIL, 2014).

Quanto aos procedimentos para coleta de dados, a estratégia utilizada foi a entrevista com apoio de questionário em pesquisa de campo. Essa técnica ocorre no mesmo local do fenômeno, portanto, possibilita o acesso a informações privilegiadas. Desta forma, quando a pesquisa de campo ocorre uma única vez, ela é classificada como transversal, ou de seção cruzada. Concluída a etapa das entrevistas, os dados passaram por tratamento quantitativo, sendo que essa abordagem privilegia a mensuração para compreender os fenômenos investigados.

Na composição da amostra, além dos concluintes do curso de Administração, foram sorteados mais cinco cursos para a investigação. O sorteio ocorreu entre os 74 cursos oferecidos pela instituição. Apesar de o sorteio ser um procedimento aleatório, a técnica de amostragem utilizada na pesquisa foi não probabilística por acessibilidade, pois não foi possível garantir aleatoriedade em todas as etapas do estudo. Assim, ao final da pesquisa de campo, foram obtidos 205 questionários de pesquisa válidos, que foram respondidos por estudantes dos cursos de Administração, Ciências Econômicas, Ciências Contábeis, Engenharia Civil, Engenharia de Alimentos e Psicologia. Conforme padrões de ética de pesquisa com seres humanos, os entrevistados assinaram o Termo de Consentimento Livre e Esclarecido (TCLE).

O questionário utilizado na pesquisa foi formado por três seções: duas seções foram destinadas aos construtos mostrados no Quadro 1 e uma seção concentrou-se no perfil sociodemográfico dos entrevistados. Assim, a primeira seção do questionário foi formada por dez afirmativas da Escala de Autoeficácia Geral Percebida (SCHWARZER; JERUSALEM, 1995), a segunda, também com dez afirmativas, investigou a autopercepção de empregabilidade (PEIXOTO; JANISSEK; AGUIAR, 2015) e a terceira reuniu informações dos entrevistados quanto a aspectos como idade, curso, estado civil, entre outros. As respostas foram de múltipla escolha e em escala de Lickert, com sete opções de respostas, sendo um para discordo totalmente, até sete para concordo totalmente.

O tratamento de dados utilizou técnicas descritivas, inferenciais e multivariadas. Quanto às técnicas descritivas, foram empregadas a distribuição de frequências, as medidas de dispersão e de tendência central. Essas técnicas foram utilizadas para possibilitar a exploração inicial dos dados e observar como os entrevistados se posicionavam em relação aos fenômenos investigados. Para atender ao objetivo principal da pesquisa, foi feita uma análise de regressão linear múltipla (RLM). Esse procedimento possibilitou estabelecer o 
modelo e compreender quanto da variável dependente (autopercepção de empregabilidade) estava associada aos aspectos da variável independente (autoeficácia).

\begin{tabular}{|c|c|}
\hline \multirow{10}{*}{ 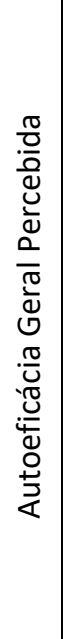 } & V01. Consigo resolver sempre os problemas difíceis se for persistente. \\
\hline & V02. Se alguém se opuser, consigo encontrar os meios e as formas de alcançar o que quero. \\
\hline & V03. Para mim, é fácil agarrar-me às minhas intenções e atingir meus objetivos. \\
\hline & V04. Estou confiante que poderia lidar eficientemente com acontecimentos inesperados \\
\hline & V05. Graças a meus recursos, sei como lidar com situações imprevistas. \\
\hline & V06. Consigo resolver a maioria dos problemas se investir o reforço necessário. \\
\hline & V07. Perante dificuldades, consigo manter a calma porque confio nas minhas capacidades. \\
\hline & V08. Quando confrontado com um problema, consigo geralmente encontrar várias soluções. \\
\hline & V09. Se estiver com problemas, consigo geralmente pensar numa solução. \\
\hline & V10. Consigo geralmente lidar com tudo aquilo que me surge pelo caminho. \\
\hline \multirow{9}{*}{ 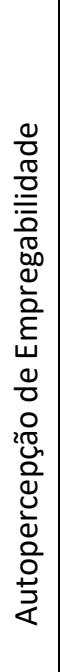 } & V11. Sinto-me capaz de vencer os obstáculos necessários para entrar em uma organização. \\
\hline & $\begin{array}{l}\text { V12. Caso saísse do meu emprego atual (ou estágio), eu não teria dificuldade para conseguir outro } \\
\text { emprego. }\end{array}$ \\
\hline & V13. Sinto que tenho conhecimentos e habilidades importantes para o mercado de trabalho. \\
\hline & $\begin{array}{l}\text { V14. Minha experiência profissional me garante uma vantagem na hora de concorrer a uma vaga de } \\
\text { emprego. }\end{array}$ \\
\hline & V15. Considero que sou capaz de aprender novas habilidades para conseguir um trabalho. \\
\hline & V16. Acredito que outra empresa tenha interesse em me contratar. \\
\hline & $\begin{array}{l}\text { V17. Mesmo diante das atuais dificuldades de inclusão no mercado de trabalho, não me sinto } \\
\text { ameaçado. }\end{array}$ \\
\hline & V18. A competição no mercado de trabalho não me aflige. \\
\hline & V19. Não me sinto ameaçado de perder esse emprego. \\
\hline
\end{tabular}

Fonte: Schwarzer e Jerusalem (1995) e Peixoto Janissek e Aguiar (2015).

$\mathrm{Na}$ etapa seguinte, foram feitos testes de hipóteses (Teste $\mathrm{T}$ para amostras independentes) para verificar se as diferenças encontradas entre as médias dos grupos investigados, Administração (n1) e demais cursos (n2), eram significativas, ou ocorriam por obra do acaso. Com isso, foi possível inferir se as diferenças entre a autoeficácia e a autopercepção de empregabilidade entre os concluintes de Administração e dos outros cursos da instituição eram significativas. O nível de significância estatística adotado no critério de decisão foi de $5 \%$.

\section{APRESENTAÇÃO DE RESULTADOS}

Os entrevistados eram estudantes do último ano em 100\% (205) das observações, sendo predominantemente solteiros $(84,9 \%)$, do sexo masculino $(55,1 \%)$, e sem filhos $(70,7 \%)$. Na maioria dos casos, faziam o curso no período noturno $(64,4 \%)$, exerciam atividade remunerada $(78,5 \%)$, com jornada de trabalho de até 40 horas semanais $(69,3 \%)$, atuando em atividades relacionadas com o curso (62,4\%). Quanto à atividade profissional, os participantes tinham vínculo empregatício regular $(81,5 \%)$ nos termos da Consolidação das 
Leis do Trabalho (CLT) ou do Regime Jurídico Único (RJU). Distribuídos em seis cursos de graduação, a amostra incluiu Administração (45,6\%), Ciências Contábeis (17\%), Ciências Econômicas (15,5\%), Engenharia Civil (8,7\%), Engenharia de Alimentos (6,8\%) e Psicologia $(6,4 \%)$. A renda familiar foi de até $\mathrm{R} \$ 4.861,00$ por mês $(75,1 \%)$. De maneira geral, os entrevistados avaliaram o mercado de trabalho como estável (44,4\%), sendo o concurso público $(25,8 \%)$ a principal alternativa de carreira para o futuro.

A consistência interna da autoeficácia e da autopercepção de empregabilidade foi medida pelo coeficiente alpha de Cronbach. Os resultados revelaram elevada confiabilidade, tanto para a autoeficácia $(\alpha=0,905)$, quanto para a autopercepção de empregabilidade $(\alpha=0,891)$. A análise de correlação de Pearson, calculada pela média dos scores, revelou correlação positiva, com intensidade moderada e significativa entre os construtos $(r=0,683$, $p$-valor $=0,000)$, reforçando a compreensão de que a autoeficácia e a autopercepção de empregabilidade apresentam comportamentos lineares no mesmo sentido. Correlações positivas e significativas com diferentes intensidades foram encontradas em outros estudos que relacionaram a autoeficácia com habilidades sociais, decisões, clareza, autoconceito e comportamento exploratório (BARDAGI; BOFF, 2010).

\subsection{AUTOEFICÁCIA E AUTOPERCEPÇÃO DE EMPREGABILIDADE}

Para investigar características da autoeficácia e sua relação com a autopercepção de empregabilidade, foi feita uma regressão linear múltipla (MQO), que teve como variável dependente o somatório dos escores da autopercepção de empregabilidade e como variáveis independentes as dez afirmativas da escala da autoeficácia. O procedimento utilizado para seleção dos preditores foi o backward. O modelo, mostrado na Tabela 1, foi capaz de explicar 49,85\% (R-quadrado ajustado) da autopercepção de empregabilidade e mostrou bom ajuste, uma vez que, a Estatística $F$ foi significativa a $1 \%$, houve distribuição normal e independente dos resíduos e a ausência de multicolinearidade (Estatística VIF (V03) $=1,45 ;$ VIF (V06) =1,60; VIF (V07) =1,92; VIF (V10) =1,51; VIF (Diurno) =1,03).

Tabela 1 - Regressão linear múltipla para autopercepção de empregabilidade

\begin{tabular}{ccccc}
\hline Variável & Coeficiente & Erro Padrão & Estatística T & P-valor \\
\hline C & 9,882810 & 3,174306 & 3,113376 & 0,0021 \\
V03 & 1,737670 & 0,529619 & 3,280979 & 0,0012 \\
V06 & 1,439816 & 0,615151 & 2,340590 & 0,0202 \\
V07 & 2,663251 & 0,554178 & 4,805768 & 0,0000 \\
V10 & 1,399180 & 0,495718 & 2,822531 & 0,0052 \\
Diurno & $-3,793776$ & 1,135145 & $-3,342107$ & 0,0010 \\
\hline R-Quadrado & 0,510851 & Estatística F & 41,56587 \\
R-Quadrado Ajustado & 0,498561 & P-valor (F) & 0,00000 \\
& & Estatística Durbin-Watson & 1,845066
\end{tabular}

Nota: V03 = para mim é fácil agarrar-me às minhas intenções e atingir meus objetivos; V06 = consigo resolver a maioria dos problemas se investir o reforço necessário; V07 = perante dificuldades, consigo manter a calma porque confio nas minhas capacidades; $\mathrm{V} 10$ = consigo geralmente lidar com tudo aquilo que me surge pelo caminho. Diurno = dummy referente ao turno do curso. Anova: significativo; Teste de aleatoriedade: aceita a hipótese de aleatoriedade; Teste de normalidade de resíduos: aceita a hipótese de distribuição normal (JaqueBera $=2,480961$, p-valor=0,289245); Teste de homocedasticidade: aceita a hipótese de homocedasticidade (Teste de White, $\mathrm{F}=1,054755$, $\mathrm{p}$-valor=0,4015).

Fonte: Dados da pesquisa. 
O resultado da regressão mostrou que a autopercepção de empregabilidade teve associação positiva com as variáveis V03, V06, V07 e V10 da autoeficácia. A variável Diurno (dummy) foi inserida no modelo na forma aditiva, com a finalidade de captar diferenças entre os turnos diurno ou noturno e assim identificar se os concluintes de turnos diferentes apresentam diferenças entre si. Os resultados do modelo indicam que a capacidade de estabelecer objetivos, a determinação e o autocontrole, além da calma e da capacidade de lidar com problemas, contribuem para o aumento da autopercepção de empregabilidade. A composição dessas variáveis reforça a compreensão de que a percepção de empregabilidade depende em grande parte do próprio comportamento individual (COLETA et al., 2002).

Os resultados do modelo estão alinhados com estudos de Luthans, Youssef e Avolio (2007) e Liu et al. (2014), ao destacarem que a percepção de empregabilidade está fundamentada na autoeficácia (LUTHANS; YOUSSEF; AVOLIO, 2007; LIU et al., 2014), na expectativa, na resiliência e no otimismo (LUTHANS; YOUSSEF; AVOLIO, 2007). Assim, indivíduos que apresentam essas características de forma mais presente, além de acreditarem na própria empregabilidade, desenvolvem estratégias mais eficientes para lidar com o estresse e as eventuais frustrações inerentes às mudanças ocorridas nas diversas fases da carreira profissional. Coleta et al. (2002) reforçam essa compreensão ao afirmarem que existe um locus de controle interno no qual os indivíduos atribuem a si mesmos sua própria empregabilidade.

No mesmo sentido, Bandura (2001) destaca que o senso de competência contribui positivamente para a obtenção dos resultados esperados. Os resultados encontrados no modelo em estudo foram coerentes com diversos estudos (TEIXEIRA; GOMES, 2004; BARDAGI; BOFF, 2010), que, pautados na Teoria Social Cognitiva (TSC), reforçam que quanto mais o indivíduo conhece o papel a ser desempenhado, maior será sua segurança para superar adversidades e adaptar-se a novas situações ou a processos de mudança.

Ao analisar a variável Diurno, o sinal negativo nessa variável revela que a realização do curso no período diurno reduz a autopercepção de empregabilidade. Uma hipótese para essa constatação pode ser o resultado da menor experiência com a prática da profissão em decorrência de as aulas ocorrerem durante o dia, aspecto que, em certa medida, limita a oferta de empregos. Nesse sentido, Bardagi e Boff (2010) destacam que estudantes cuja formação se detém muito fortemente a formação curricular, com pouca, ou sem prática profissional, tendem a ser mais pessimistas quanto a suas expectativas.

Nesse aspecto, destaca-se a experiência vicária apresentada por Bandura (2001), em que o indivíduo ao ver outras pessoas progredindo e conquistando posições na vida aprendem e passam a acreditar nas próprias capacidades. Nesse contexto, a experiência prática na profissão contribui para uma melhor autopercepção de empregabilidade e para a aproximação com a prática profissional necessária para proporcionar essa vivência, na medida em que a autoeficácia é um determinante de ações do indivíduo.

\subsection{DIFERENCAS E SEMELHANÇAS ENTRE CONCLUINTES DE ADMINISTRAÇÃO E OUTROS CURSOS}

A avaliação da autoeficácia (Tabela 2), mostrou que, na maioria das variáveis, não há diferença significativa entre as médias das respostas dos concluintes de administração e dos demais cursos investigados. As únicas diferenças foram "Graças aos meus recursos, sei como lidar com situações imprevistas" (V5, 5,11 vs. 4,60, p-valor=0,001) e "Consigo geralmente lidar com tudo aquilo que me surge pelo caminho" (V10, 5,26 vs. 4,91, p- 
valor $=0,001$ ), sendo que em ambos os casos, a média dos concluintes de administração foi pouco superior à média dos demais cursos reunidos. Esse aspecto sugere que os estudantes de administração acreditam mais fortemente na sua capacidade de adaptação e de enfrentamento de situações imprevisíveis, quando comparados com a média dos demais cursos investigados. Uma hipótese para essa percepção está relacionada com a formação do administrador e a necessidade de lidar com situações incontroláveis e adversas, típicas dos ambientes complexos nos quais as organizações estão inseridas.

As demais variáveis da autoeficácia não mostraram diferenças significativas, possibilitando interpretar que as eventuais diferenças ocorreram ao acaso. Nessa perspectiva, todas as respostas se posicionaram acima do ponto intermediário da escala $(4,00)$, portanto, no estrato de concordância. Assim, os estudantes concluintes, de maneira geral, acreditam na sua capacidade de solucionar problemas difíceis com determinação (V01), confiam que conseguem encontrar meios para alcançar seus objetivos mesmo ao enfrentarem oposição (V02), além de terem determinação na busca pelos objetivos pessoais (V03). Eles se mostram adaptativos em situações imprevisíveis (V03) e inesperadas (V04) graças aos seus recursos (V05) e acreditam que podem solucionar a maioria dos problemas se empregarem o esforço necessário (V06). Nas dificuldades, permanecem calmos, pois confiam nas capacidades que desenvolveram (V07) e, na maioria das situações, identificam diversas alternativas para solucionar problemas (V08), para os quais geralmente encontram soluções (V09), além de frequentemente conseguirem lidar com as situações que ocorrem na vida (V10).

Tabela 2 - Comparação dos concluintes de administração (n1=94) com outros cursos (n2=111) em relação à autoeficácia

\begin{tabular}{|c|c|c|c|c|c|}
\hline \multirow{2}{*}{ Afirmativas } & & \multirow{2}{*}{$\frac{\text { Administração }}{\text { Média (DP) }}$} & \multirow{2}{*}{$\begin{array}{c}\text { Outros Cursos } \\
\text { Média (DP) } \\
\end{array}$} & \multirow{2}{*}{$\begin{array}{l}\text { Teste } \\
\mathrm{T}\end{array}$} & \multirow{2}{*}{ P-valor } \\
\hline & & & & & \\
\hline $\begin{array}{l}\text { Consigo resolver sempre os problemas difíceis se } \\
\text { for persistente. }\end{array}$ & V01 & $5,60(1,44)$ & $5,55(1,25)$ & 0,245 & 0,81 \\
\hline $\begin{array}{l}\text { Se alguém se opuser, consigo encontrar os meios e } \\
\text { as formas de alcançar o que quero. }\end{array}$ & V02 & $5,33(1,12)$ & $5,22(1,31)$ & 0,719 & 0,47 \\
\hline $\begin{array}{l}\text { Para mim é fácil agarrar-me às minhas intenções e } \\
\text { atingir meus objetivos. }\end{array}$ & V03 & $5,43(1,20)$ & $5,26(1,32)$ & 0,921 & 0,36 \\
\hline $\begin{array}{l}\text { Estou confiante que poderia lidar eficientemente } \\
\text { com acontecimentos inesperados }\end{array}$ & V04 & $5,21(1,29)$ & $4,95(1,32)$ & 1,412 & 0,16 \\
\hline $\begin{array}{l}\text { Graças a meus recursos, sei como lidar com } \\
\text { situações imprevistas. }\end{array}$ & V05 & $5,11(1,42)$ & $4,60(1,34)$ & 2,603 & 0,01 \\
\hline $\begin{array}{l}\text { Consigo resolver a maioria dos problemas se } \\
\text { investir o reforço necessário. }\end{array}$ & V06 & $5,99(1,14)$ & $5,73(1,12)$ & 1,640 & 0,10 \\
\hline $\begin{array}{l}\text { Perante dificuldades, consigo manter a calma } \\
\text { porque confio nas minhas capacidades. }\end{array}$ & V07 & $5,47(1,32)$ & $5,22(1,41)$ & 1,313 & 0,19 \\
\hline $\begin{array}{l}\text { Quando confrontado com um problema, consigo } \\
\text { geralmente encontrar várias soluções. }\end{array}$ & V08 & $5,29(1,33)$ & $4,95(1,23)$ & 1,868 & 0,06 \\
\hline $\begin{array}{l}\text { Se estiver com problemas, consigo geralmente } \\
\text { pensar uma solução. }\end{array}$ & V09 & $5,73(1,18)$ & $5,55(1,16)$ & 1,125 & 0,26 \\
\hline $\begin{array}{l}\text { Consigo geralmente lidar com tudo aquilo que me } \\
\text { surge pelo caminho. }\end{array}$ & V10 & $5,26(1,23)$ & $4,91(1,45)$ & 2,385 & 0,01 \\
\hline genda: DP=Desvio padrão & & & & & \\
\hline
\end{tabular}

Fonte: Dados da pesquisa.

A autopercepção de empregabilidade, Tabela 2, foi elevada entre os estudantes apesar das médias serem um pouco menores do que as alcançadas pela autoeficácia. Contudo, nenhuma variável se posicionou nos estratos mais baixos da escala, que indicaria 
discordância. A única exceção ocorreu com a variável V18 (4,13 vs. 3,84, p-valor=0,261), que teve média muito próxima ao centro da escala, portanto, pouco conclusiva quanto aos efeitos da competição no mercado de trabalho, aspecto que divide a opinião dos entrevistados.

Peixoto, Janissek e Aguiar (2015) destacam que a autopercepção de empregabilidade se estrutura em duas dimensões. A primeira, denominada de autopercepção de "manutenção do emprego" indica a segurança quanto à conservação do emprego atual. Essa dimensão reúne as variáveis de V11 a V16 e a segunda, denominada de "aquisição de novo emprego", identifica a convicção pessoal de que, caso deseje ou seja necessário, o entrevistado poderá conseguir outro emprego com relativa facilidade, sendo essa dimensão medida pelas variáveis de V17 a V20.

Tabela 3 - Comparação dos concluintes de administração (n1=94) e outros cursos (n2=111) em relação à autopercepção de empregabilidade

\begin{tabular}{|c|c|c|c|c|c|}
\hline Afirmativas & & $\frac{\text { Administração }}{\text { Média (DP) }}$ & $\begin{array}{c}\text { Outros Cursos } \\
\text { Média (DP) } \\
\end{array}$ & $\begin{array}{l}\text { Teste } \\
\mathrm{T}\end{array}$ & P-valor \\
\hline $\begin{array}{l}\text { Sinto-me capaz de vencer os obstáculos } \\
\text { necessários para entrar em uma organização. }\end{array}$ & V11 & $5,67(1,16)$ & $5,54(1,18)$ & 0,790 & 0,430 \\
\hline $\begin{array}{l}\text { Caso saísse do meu emprego atual (ou estágio), eu } \\
\text { não teria dificuldade de conseguir outro emprego. }\end{array}$ & V12 & $4,80(1,68)$ & $4,39(1,59)$ & 1,793 & 0,740 \\
\hline $\begin{array}{l}\text { Sinto que tenho conhecimentos e habilidades } \\
\text { importantes para o mercado de trabalho. }\end{array}$ & V13 & $5,69(1,15)$ & $5,42(1,26)$ & 1,581 & 0,116 \\
\hline $\begin{array}{l}\text { Minha experiência profissional me garante uma } \\
\text { vantagem na hora de concorrer a uma vaga de } \\
\text { emprego. }\end{array}$ & V14 & $5,45(1,44)$ & $4,63(1,58)$ & 3,691 & 0,000 \\
\hline $\begin{array}{l}\text { Considero que sou capaz de aprender novas } \\
\text { habilidades para conseguir um trabalho. }\end{array}$ & V15 & $6,46(0,80)$ & $6,32(1,08)$ & 0,998 & 0,324 \\
\hline $\begin{array}{l}\text { Acredito que outra empresa tem interesse em me } \\
\text { contratar. }\end{array}$ & V16 & $4,97(1,50)$ & $4,69(1,30)$ & 1,408 & 0,161 \\
\hline $\begin{array}{l}\text { Mesmo diante das atuais dificuldades de inclusão } \\
\text { no mercado de trabalho, não me sinto ameaçado. }\end{array}$ & V17 & $4,47(1,78)$ & $4,11(1,66)$ & 1,499 & 0,136 \\
\hline $\begin{array}{l}\text { A competição no mercado de trabalho não me } \\
\text { aflige. }\end{array}$ & V18 & $4,13(1,83)$ & $3,84(1,84)$ & 1,127 & 0,261 \\
\hline Não me sinto ameaçado de perder esse emprego. & V19 & $4,72(1,77)$ & $4,37(1,72)$ & 1,456 & 0,147 \\
\hline $\begin{array}{l}\text { Minha competência faz com que eu não precise } \\
\text { me preocupar em perder outro emprego. }\end{array}$ & V20 & $4,43(1,72)$ & $4,06(1,67)$ & 1,528 & 0,128 \\
\hline
\end{tabular}

Legenda: DP=Desvio padrão

Fonte: Dados da pesquisa.

Entre as variáveis com a maior concordância, destacaram-se três: "Considero que sou capaz de aprender novas habilidades para conseguir um trabalho" (V15, 6,46 vs. 6,32, pvalor=0,324), "Sinto que tenho conhecimentos e habilidades importantes para o mercado de trabalho" (V13, 5.69 vs. 5,42, p-valor=0,116) e "Sinto-me capaz de vencer os obstáculos necessários para entrar em uma organização" (V11, 5,67 vs. 5,54, p-valor=0,430), todas relacionadas com a manutenção do emprego.

Peixoto, Janissek e Aguiar (2015) destacam que, de maneira geral, os entrevistados sobrevalorizam a própria empregabilidade. No entanto, Ferreira (2010), em investigação com estudantes de administração, concluiu que aqueles que não trabalhavam eram mais confiantes em relação à facilidade de alcançar seus objetivos com esforço e sustentados nas próprias habilidades. Mesmo assim, na transição para o mercado de trabalho, a falta de 
planejamento de carreira representa um problema para os jovens profissionais e as instituições, que poderiam contribuir mais incisivamente, em geral, atuam muito pouco para atenuar as incertezas dessa fase, como destacam Teixeira (2002) e Bardagi e Boff (2010).

Ao analisar as diferenças entre os grupos, nota-se que apenas a variável "Minha experiência profissional me garante uma vantagem na hora de concorrer a uma vaga de emprego" (V14, 5,45 vs. 4,63, p-valor=0,000) mostrou diferença significativa entre os grupos. Essa variável, que obteve maior concordância entre os concluintes de administração, indica que a vivência na profissão é considerada uma vantagem na disputa das vagas oferecidas no mercado de trabalho. A experiência prática é destacada por Teixeira (2002) como elemento que contribui positivamente para a empregabilidade e, de certa forma, é evidenciada no mercado de trabalho, mesmo para justificar a escolha de um candidato em detrimento dos demais.

Nesse sentido, a experiência profissional pode ser favorecida pela oferta de estágios e empregos, sendo favorecida pela grande diversidade de áreas de atuação do administrador, como gestão de pessoas, finanças, produção, marketing, entre outras. Ou ainda, pela amplitude da atuação desse profissional, que encontra oportunidades em organizações públicas e privadas, nos mais diversos setores da economia. Esse aspecto sugere, pelo menos em parte, uma condição que fortalece o julgamento pessoal quanto a própria empregabilidade. Quanto às demais variáveis da autopercepção de empregabilidade, não ocorreram diferenças significativas, podendo, assim, ser interpretadas como semelhantes entre os cursos investigados.

Por outro lado, as variáveis que obtiveram médias menores, revelando aspectos de menor segurança entre os entrevistados, foram predominantemente relacionadas com a aquisição de novo emprego, mais especificamente, representadas pelas variáveis "Caso saísse do meu emprego atual (ou estágio), eu não teria dificuldade de conseguir outro emprego" (V12, 4,80 vs. 4,39, $p$-valor=0,430); "Acredito que outra empresa tem interesse em me contratar" (V16, 4,97 vs. 4,69, p-valor=0,161); "Mesmo diante das atuais dificuldades de inclusão no mercado de trabalho, não me sinto ameaçado" (V17, 4,47 vs. 4,11, pvalor=0,136); "A competição no mercado de trabalho não me aflige" (V18; 4,13 vs. 3,84, pvalor=0,261); e "Minha competência faz com que eu não precise me preocupar em perder outro emprego" (V20, 4,43 vs. 4,06, p-valor=0,128).

Esses resultados mostram que os entrevistados são confiantes na própria empregabilidade, achados semelhantes ocorreram em diversos estudos (SANTOS; MOGNOM; JOLY, 2011; TEIXEIRA; GOMES, 2004; PELISSONI, 2007). Contudo, apesar da segurança quanto à própria empregabilidade, a busca pelo novo emprego é percebida com cautela pelo entrevistado. Esse resultado pode ser reflexo da crise econômica pela qual o país vem passando nos últimos anos, posto que a perspectiva de empregabilidade recebe influência das condições do ambiente econômico (TEIXEIRA, 2002).

\section{CONSIDERAÇÕES FINAIS}

Esta pesquisa teve por objetivo investigar a autoeficácia e a autopercepção de empregabilidade entre estudantes concluintes do ensino superior no processo de transição para o mercado de trabalho, fazendo uma comparação entre estudantes de administração e estudantes de outros cursos (ciências contábeis, ciências econômicas, engenharia civil, engenharia de alimentos e psicologia). Os resultados revelam que, de maneira geral, tanto os estudantes de administração quanto os estudantes dos demais cursos se consideram 
pessoas autoeficazes e percebem de maneira positiva sua empregabilidade nesse momento da construção da carreira.

Os dados do estudo indicam ainda que os concluintes de administração se sentem mais seguros quanto à experiência profissional, ou seja, entre estes estudantes, a vivência no mercado de trabalho é considerada uma vantagem na hora de competir por uma vaga de emprego. Além disso, a análise sobre diferenças entre grupos revelou que, embora todos os concluintes entrevistados confiem em sua empregabilidade, existe uma preocupação considerável no que diz respeito à obtenção de um novo emprego, isto é, conseguir um novo trabalho é algo que denota certa apreensão entre os concluintes, mesmo que se sintam seguros em relação à própria empregabilidade.

Foi utilizada uma regressão linear múltipla para identificar quais variáveis da autoeficácia estavam relacionadas com a autopercepção de empregabilidade, e o resultado foi que a autopercepção de empregabilidade está associada a quatro variáveis da autoeficácia, isto quer dizer que a aptidão para estabelecer objetivos, a determinação, o autocontrole e a resiliência são características que contribuem para o aumento da autopercepção da empregabilidade.

Os resultados observados apontam para a importância em fortalecer a acreditação nas capacidades individuais dos futuros profissionais, assim, as instituições de ensino devem contribuir não apenas para a construção de habilidades técnicas, mas também para o fortalecimento da confiança pessoal nas próprias capacidades. Estimular o aprendizado e oferecer mais oportunidades de experiência profissional durante o período do curso também são maneiras favoráveis para o fortalecimento das crenças de autoeficácia e autopercepção de empregabilidade. Vale ressaltar que os resultados identificados no presente estudo sofrem restrições quanto à generalização em razão da natureza da coleta de dados. Sugere-se que o estudo seja ampliado para instituições de ensino privadas e públicas para verificar a existência de diferenças entre elas e se os resultados encontrados na presente investigação ocorrerão também em outras instituições e diferentes cursos superiores.

\section{REFERÊNCIAS}

ALMEIDA, A. J. Empregabilidade, contextos de trabalho e funcionamento do mercado de trabalho em Portugal. Sísifo: Revista da Ciência da Educação, n. 2, p. 51-58, jan./abr. 2007.

BANDURA, A. Human agency in social cognitive theory. The American Psychological Association, v. 44, n. 9, p. 1175-1184, 1989. DOI: <https://doi.org/10.1037/0003066X.44.9.1175>.

BANDURA, A. Self-efficacy. In: RAMACHAUDRAN, V. S. Encyclopedia of human behavior. New York: Academic Press, 1994.

BANDURA, A. Social cognitive theory: an agentic perspective. Annual Reviews Psychology, v. 52, n. 1, p. 1-26, 2001.

BARDAGI, M. P.; BOFF, R. Autoconceito, autoeficácia profissional e comportamento exploratório em universitários concluintes. Avaliação, v. 15, n. 1, p. 41-56, 2010. 
CHEN, D. J. Q.; LIM, V. K. G. Strength in adversity: The influence of psychological capital on job search. Journal of Organizational Behavior, v. 33, n. 8, p. 11-839, 2012.

COLETA, M. F. D.; MACHADO, L. M.; OLIVEIRA, D. S.; SPOSITO, L. S.; GONÇALVES, C. A. B. Percepções e sentimentos diante da empregabilidade. Revista da Sociedade de Psicologia do Triângulo Mineiro, v. 6, n. 1, p. 37-42, jan./jun. 2002.

CORREIA, R. F. C. Autoeficácia na transição para o trabalho e percepção de barreiras em alunos do 12ㅇ ano de cursos profissionais. 2011. 70 f. Dissertação (Mestrado em Psicologia) - Faculdade de Psicologia, Universidade de Lisboa, Lisboa, 2011.

FERNANDES, V. M. P. Adaptação académica e autoeficácia em estudantes universitários do 10 ciclo de estudos. 2011. 165 f. Dissertação (Mestrado em Psicologia) - Faculdade de Ciências Humanas e Sociais, Universidade Fernando Pessoa, Porto, 2011.

FERREIRA, S. M. S. Autoeficácia de alunos de administração: um estudo com concluintes do curso de graduação em Administração no Estado do Pará. 2010. 92 f. Dissertação (Mestrado em Administração) - Programa de Pós-Graduação em Administração, Universidade Federal do Rio Grande do Norte, Natal, 2010.

FERREIRA FILHO, E. P.; ANDRADE, A. F. SOUZA, L. Q. A administração e os desafios da contemporaneidade: a percepção dos acadêmicos do curso de Administração quanto ao desenvolvimento de sua empregabilidade. In: SIMPÓSIO DE EXCELÊNCIA EM GESTÃO E TECNOLOGIA: Gestão e Tecnologia para a Competitividade, 10. 2013. Anais [...]. Resende: AEDB, 2013. Disponível em: https://www.aedb.br/seget/arquivos/artigos13/43318478.pdf.

GIL, A. C. Métodos e técnicas de pesquisa social. São Paulo: Atlas, 2014.

GLASER, S. L.; BARDAGI, M. P. Habilidades sociais, autoeficácia e decisão de carreira em universitários em no final de curso. Boletim Academia Paulista de Psicologia, v. 80, n. 1, p. 148-165. 2011.

GOMES, N. A. S. Autoestima, autoeficácia e empregabilidade subjectiva em empregados, desempregados e estudantes do ensino superior. 2014. 80 f. Dissertação (Mestrado em Psicologia) - Escola de Psicologia e Ciências da Vida, Universidade Lusófona de Humanidades e Tecnologias, Lisboa, 2014.

NSTITUTO NACIONAL DE ESTUDOS E PESQUISAS EDUCACIONAIS ANÍSIO TEIXEIRA. Censo Nacional de Cursos Superiores de 2018. Disponível em: http://portal.inep.gov.br/censo-daeducacao-superior. Acesso em: 05 maio 2020.

KANFER, R.; WANBERG, C. R.; KANTROWITZ, T. M. Job search and employment: A personality motivation analysis and metaanalytic review. Journal of Applied Psychology, v. 86, n. 5, p. 837-855, 2001. 
LAMAS, K. C. A.; AMBIEL, R. A. M.; SILVA, B. T. A. O. L. Vivências acadêmicas e empregabilidade de universitários em final de curso. Temas em psicologia, v. 22, n. 2, p. 329-340, 2014.

LIU. S.; WANG, M.; LIAO, H.; SHI, J. Self-regulation during job search: the opposing effects of employment self-efficacy and job search behavior self-efficacy. Journal of Applied Psychology, v. 99, n. 6, p. 1159-1172, 2014.

LUTHANS, F; YOUSSEF, C.; AVOLIO, B. Psychological capital: developing the human competitive edge. New York: Oxford University Press, 2007.

MAGALHÃES, M. O.; TEIXEIRA, M. A. P. Antecedentes de Comportamentos de Busca de Emprego na Transição da Universidade para o Mercado de Trabalho. Psicologia: Teoria e Pesquisa, v. 29, n. 4, p. 411-419, out./dez. 2013.

MALSCHITZKY, N. Empregabilidade: um modelo para a instituição de ensino superior orientar e encaminhar a carreira profissional dos acadêmicos. 2004. 177 f. Tese (Doutorado em Engenharia de Produção) - Programa de Pós-Graduação em Engenharia de Produção, Universidade Federal de Santa Catarina, Florianópolis, 2004.

MARTÍNEZ, I. M.; SALANOVA, M. Autoeficacia en el trabajo: el poder de creer que tú puedes. Estudios Financieros, n. 45, 2006. Disponível em:

http://www.wont.uji.es/publicaciones/articulos/articulos-listado/item/autoeficacia-en-eltrabajo-el-poder-de-creer-que-tu-puedes. Acesso em: 20 mar. 2020.

PEIXOTO, A. L. A.; JANISSEK, J.; AGUIAR, C. V. N. Autopercepção de Empregabilidade. In: PUENTE-PALACIOS, K; PEIXOTO, A. L. A. (Org.). Ferramentas de diagnóstico para organizações e trabalho: Um olhar a partir da psicologia. Porto Alegre: Artmed Editora, 2015. p.175-186.

PELISSONI, A. M. S. Autoeficácia na transição para o trabalho e comportamento de exploração de carreira em licenciados. 2007. 167 f. Dissertação (Mestrado em Educação) Faculdade de Educação, Universidade Estadual de Campinas, São Paulo, 2007.

POLYDORO, S. A. J.; GUERREIRO-CASANOVA, D. C. Escala de autoeficácia na formação superior: construção e estudo de validação. Avaliação Psicológica, v. 9, n. 2, p. 267-278, 2010.

RAMOS, L. A.; PAIXÃO, M. P.; SILVA, J. T. O impacto da autoeficácia no desenvolvimento da identidade vocacional. Revista Psychologica, v. 44, p. 25-44, 2007.

RUEDA, F. J. M; MARTINS, L. J; CAMPOS, K. C. L. Empregabilidade: o que os alunos universitários entendem sobre isto? Psicologia: Teoria e Prática, v. 6, n. 2, p. 63-73, 2004.

SANTOS, A. A. A.; MOGNON, J. F.; JOLY, M. C. R. A. Crenças de autoeficácia na transição para o trabalho em formandos de engenharia. Revista Brasileira de Orientação Profissional, v. 12, n. 2, p. 197-204, 2011. 
SCHWARZER, R.; JERUSALEM, M. Generalized self-efficacy scale. In: WEINMAN, J.; WRIGHT, S.; JOHNSTON, M. Measures in health psychology: a user's portfolio. Causal and control beliefs. Windsor, England: NFER-Nelson, 1995.

SILVA, M. C. R.; FERRAZ, V. E.; OSWALDO, Y. C. Auto-Eficácia: Uma avaliação do formando universitário frente à transição para o mercado de trabalho. Encontro: Revista de Psicologia, v. 15, n. 22, p. 107-120, 2012.

TEIXEIRA, M. A. P. A experiência de transição entre a universidade e o mercado de trabalho na adultez jovem. 2002. $168 \mathrm{f}$. Tese (Doutorado em Psicologia) - Instituto de Psicologia, Universidade Federal do Rio Grande do Sul, Porto Alegre, 2002.

TEIXEIRA, M. A. P.; GOMES, W. B. Estou me formando... e agora? Reflexões e perspectivas de jovens formandos universitários. Revista Brasileira de Orientação Profissional, v. 5, n. 1, p. 47-62, 2004.

WANBERG, C. R.; KANFER, R.; ROTUNDO, M. Unemployed individuals: Motives, job-search competencies, and job search constrains as predictors of job seeking and reemployment. Journal of Applied Psychology, v. 84, n. 6, p. 897-910, 1999.

ZIKIC, J.; SAKS, A. M. Job search and Social Cognitive Theory: The role of career-relevant activities. Journal of Vocational Behavior, v. 74, n. 1, p. 117-127, 2009. 